\title{
THE ABSORPTION OF FATS STUDIED IN A CHILD WITH CHYLOTHORAX
}

\author{
By J. FERNANDES, J. H. VAN DE KAMER, AND H. A. WEIJERS \\ (From the Pediatric Department of the University Hospital, Leyden, The Netherlands and the \\ Central Institute for Nutrition Research T.N.O., Utrecht, The Netherlands)
}

(Submitted for publication September 9, 1954 ; accepted March 2, 1955)

The way in which fat is absorbed in healthy people is still largely unknown. This lack of knowledge chiefly concerns the question whether complete hydrolysis of the dietary fat is necessary before it is absorbed, or whether absorption through the intestinal wall is possible without complete hydrolysis. In the past few decades this problem has been studied mainly by Verzár and McDougall $(1,2)$ and by Frazer (3-12), although in widely different ways.

The quintessence of Verzár's theory is: complete hydrolysis of fat in the intestine and synthesis of the fatty acids to triglycerides in the intestinal cells, via an intermediate stage of phospholipids. The main features of Frazer's theory are : hydrolysis of part of the fat into mono- and diglycerides and free fatty acids in the intestine, formation of an emulsion and absorption of tiny droplets of fat. The essential point of difference between these two theories is the degree of hydrolysis of the fat in the intestine. This problem has been approached in various ways.

The degree of hydrolysis was determined directly by examination of the intestinal contents after administration of fat by Mattson, Benedict, Martin, and Beck (13), Desnuelle and Constantin (14) and Kuhrt and other workers (15). Other attempts to determine the degree of hydrolysis using an indirect method of calculation, by comparison of chyle fat with dietary fat labelled with isotopes, were made by Borgström (16), Reiser, Bryson, Carr, and Kuiken $(17,18)$ and Bernhard, Wagner, and Ritzel (19). All these investigations led to the conclusion that there is a considerable hydrolysis of fat in the intestinal lumen. According to Frazer (10) about 40 per cent of the dietary fat is hydrolyzed partially, but Borgström and Reiser consider it highly probable that the hydrolysis, in any case into mono- and diglycerides, is practically complete. The latter authors assume that 25 to 45 per cent of the dietary fat is completely broken down into free fatty acids and glycerol; the remaining 55 to 75 per cent is, according to them completely, and according to Bernhard partially, hydrolyzed into monoglycerides.

There is, however, quite another aspect to this problem. Frazer (6-9), Bernhard (20), Borgström $(21,22)$, Bloom, Chaikoff, and Reinhardt (23) and Favarger (24) have shown that not all fatty acids are absorbed in the same manner.

According to Frazer the fatty acids of low molecular weight are absorbed in a different manner from those of high molecular weight. Frazer also deals separately with the unsaturated fatty acids, such as $\Delta^{\theta}$-octadecanoic acid. As the dietary fats may be of widely varying composition, the determination of the individual absorption of all fatty acids, of which the dietary fat concerned is composed, is of great advantage, in contrast to the determination of the total absorption of fat or of the absorption of one particular labelled fatty acid.

The method of Boldingh $(25,26)$ enables such an analysis. A case of chylothorax in a child offered us a welcome opportunity to use this method in order to study the absorption of the separate fatty acids (27).

\section{CLINICAL FEATURES}

Chylothorax is a rare anomaly, arising when the pleural cavity of one or both lungs fills with chyle. The anomaly is caused by a lesion of a chyle vessel. The patient who gave us the opportunity of conducting this investigation was the third child of healthy parents; he was born on July 13, 1950. The other children were healthy. The mother's pregnancy was uneventful; parturition was normal. Directly following birth it was noticed that the patient had a swollen abdomen and a bilateral testicular hydrocele. When the boy was two months old, operation on a bilateral inguinal hernia (which had developed gradually) revealed that the swollen abdomen was due to chyloascites. Seven months later, a right-sided chylothorax was found in addition. 
The signs and symptoms of chylothorax and chyloascites alternated in predominance, without any operation being necessary, up to the age of nearly two years. Then he began to have attacks of dyspnea until he was admitted to the hospital, because of the severity of the dyspnea, at the age of 22 months.

On examination no other abnormalities were found apart from a barrel-shaped thorax and much fluid in the right pleural cavity. There was no fluid in the abdominal cavity. Feces, urine and blood were normal on morphological and chemical examination. Liver function and fat balance were also normal (the latter had been disturbed only for a short period during and after an infection). Although the patient's nutritional condition was not optimal, his growth during his affection and after recovery from it was always normal. On the strength of these data the patient was regarded as a healthy child with a purely anatomical abnormality. It may therefore be assumed that the chyle of this patient was also normal.

The right pleural cavity was drained weekly by aspiration during his eight months' stay in the Pediatrics Department. The secretion of chyle into the pleural cavity diminished during the last few weeks of this period and had ceased completely at the end of the eight months. So far relapses have remained absent and, at the time of writing, the child is in good condition.

The patient's chyle came up to the requirements of Baldridge and Lewis (28): 1) its color was that of milk; 2) a cream-like upper layer separated from the fluid at rest; 3 ) it was an emulsion of fine fat droplets; 4) its reaction was alkaline; 5) the fluid was sterile and not liable to decomposition; 6) the fat content was usually high, varying between 0.4 and 4.0 per cent ; 7 ) the protein content was usually more than 3.0 per cent; 8 ) the fluid contained many lymphocytes. It appeared moreover that: the fat content of the chyle was dependent on the fat content of the diet; and, the fatty acid composition of the chyle fat was dependent on the fatty acid composition of the dietary fat. These relationships are characteristic of chyle and constitute proof that the fluid aspirated from the thoracic cavity was actually chyle. Results of laboratory examinations are shown in Table I.

\section{EXPERIMENTAL}

\section{Aim of the investigation}

The aim of the investigation was to study the relationship between dietary fat and chyle fat, to arrive at conclusions on the absorption of fats in man, and to test these conclusions against the current theories on the mechanism of fat absorption.
TABLE I

Some characteristics of the patient's chyle

\begin{tabular}{|c|c|c|c|}
\hline & $\begin{array}{l}\text { Number } \\
\text { of deter- } \\
\text { minations }\end{array}$ & Range & Average \\
\hline $\begin{array}{c}\text { Cells (mainly mono- } \\
\text { nuclears) }\end{array}$ & 18 & $(900-6000)$ & $3000 / \mathrm{mm}^{2}$ \\
\hline $\begin{array}{l}\text { Protein (Kjeldahl) } \\
\text { Albumin } \\
(\alpha+\beta)-G l o b u l i n \\
\gamma-\text { Globulin }\end{array}$ & $\begin{array}{l}6 \\
6 \\
6 \\
6\end{array}$ & $\begin{array}{l}(3.37-4.57) \\
(1.79-2.54) \\
(0.14-0.60) \\
(0.77-2.31)\end{array}$ & $\begin{array}{l}4.00 \mathrm{gm} . \% \\
2.25 \mathrm{gm} . \% \\
0.50 \mathrm{gm} . \% \\
1.25 \mathrm{gm} . \%\end{array}$ \\
\hline $\begin{array}{l}\text { Cholesterol } \\
\text { Cholesterol esters }\end{array}$ & $\begin{array}{l}25 \\
25\end{array}$ & $\begin{array}{l}(90-230) \\
(60-220)\end{array}$ & $\begin{array}{l}130 \mathrm{mg} \cdot \% \\
65 \mathrm{mg} \cdot \%\end{array}$ \\
\hline $\begin{array}{l}\text { Potassium } \\
\text { Sodium } \\
\text { Calcium } \\
\text { Chloride } \\
\text { Phosphorus }\end{array}$ & $\begin{array}{l}6 \\
6 \\
6 \\
6 \\
6\end{array}$ & $\begin{array}{l}(3.7-4.2) \\
(137-141) \\
(4.5-4.8) \\
(99-109) \\
(4.9-5.1)\end{array}$ & $\begin{array}{l}4.0 \mathrm{mEq} / / \mathrm{L} \\
140 \mathrm{mEq} \cdot / \mathrm{L} \\
4.7 \mathrm{mEq} \cdot / \mathrm{L} \\
103 \mathrm{mEq} \cdot / \mathrm{L} \\
5.0 \mathrm{mg} . \%\end{array}$ \\
\hline
\end{tabular}

\section{Arrangement of the experiments}

On the strength of animal experiments and based on Munk's investigations on a patient with a chylous fistula, it is to be expected that a great deal of the fat, under normal circumstances, is absorbed with the chyle. It is, therefore, possible to study the fat absorption, at any rate that via the lymph, by comparison of the composition of chyle fat with that of dietary fat. In contrast to former investigations, it is now possible to compare the composition of the chyle fat as a whole with that of the dietary fat, by means of separate quantitative determinations of all fatty acids. As not all intestinal chyle accumulates in the patient's thorax, absolute measurement of the absorption via the lymph was not possible.

The natural fats, which are mixed triglycerides being composed of widely varying proportions of the fatty acids, n-octanoic to n-docosanoic, were administered to the patient in such a way that each time certain particular fatty acids could be studied. When the patient was given butterfat, the emphasis fell on the short-chain fatty acids, n-tetranoic, n-hexanoic, and n-octanoic; when given margarine and coconut oil, n-octanoic, n-decanoic, and n-dodecanoic acid were preponderant. A synthetic fat, "capryl olive oil," was administered to study the behavior of n-octanoic acid more closely; cacao-butter was given to examine that of $\mathrm{n}$-hexadecanoic and $\mathrm{n}$-octadecanoic acid; and finally a synthetic fat with hydrogenated herring oil was given to investigate the absorption of $\mathrm{n}$-eicosanoic and n-docosanoic acid.

The next step was to study the absorption via the lymph of some unsaturated fatty acids. By feeding sunflower oil and linseed oil the absorption of $\Delta^{0}$, ${ }^{3}$-octadecadienoic acid and $\Delta^{0}, 12$, 15 -octadecatrienoic acid was investigated, while the behavior of $\Delta^{13}$-docosenoic acid was studied by the administration of rapeseed oil. Comparison of the lymphatic absorption of olive oil and eláidinized olive oil enables us to investigate the absorption of $\Delta^{\circ}$ octadecenoic acid (both cis- and trans-isomers). 
As the lymph was aspirated only once a week, the possibility could not be excluded that some fatty acids might be absorbed from the thoracic cavity to a greater extent than others. This is, however, unlikely because the fatty acids are almost completely present as fat in the lymph. A differentiation is therefore impossible here and a specific absorption can therefore not be expected.

It is possible that part of the fat is absorbed via the portal system and the liver. This was not investigated in the case concerned. The possibility should not be overlooked that some fat escapes absorption and is excreted in the feces. In order to keep a check on this the fat balance was always determined by the method of van de Kamer (29).

The patient was kept on a diet with constant amounts of fats, proteins, and carbohydrates during most of the experiments. The daily diet consisted of:
$200 \mathrm{ml}$. protein milk ${ }^{1}$
$75 \mathrm{gm}$. green vegetable
$25 \mathrm{gm}$. lean meat
$16 \mathrm{gm}$. fat
$75 \mathrm{gm}$. banana
$50 \mathrm{ml}$. orange juice
$20 \mathrm{gm}$. rice flour
$20 \mathrm{gm}$. sugar
$400 \mathrm{ml}$. water
$50 \mathrm{gm}$. potato

$100 \mathrm{ml}$. tomato juice
Vitamins A, D, B-complex ${ }^{2}$ and $C$ were added to this diet. Stabilized ferrous chloride was also given per os. The amount of fat was $28 \mathrm{gm}$. per day; exceptions were made during some periods in which larger or smaller amounts were given. It was necessary during the last two months to increase the amounts of protein and carbohydrate in order to meet the increasing caloric demands.

The type of fat in the diet was changed every week, or group of weeks, by giving a protein milk and fat containing different kinds of glycerides, such as coconut oil or olive oil instead of butterfat.

The chyle was collected by pleural puncture at the end of each week, and subsequently the pleural cavity was examined radiologically for the presence of chylous residues. Because of the possibility that a slight residue may influence the composition of the chyle during the following dietary period, a diet containing one kind of fat was usually given for two successive weeks. The composition of the chyle fat during the second week was considered the most representative.

\section{Methods}

The chemical investigation was carried out as follows: All saturated fatty acids with the exception of

1 The protein milk was prepared by Nutricia, Ltd., of Zoetermeer, The Netherlands, and consisted of a base of buttermilk in which $5.5 \mathrm{gm}$. per $100 \mathrm{ml}$. butterfat, coconut oil, olive oil, etc. were emulsified without the addition of an emulsifier. In some periods the fat was emulsified in skimmed milk.

2 One tablet of Vitamin B-complex daily was administered, containing: thiamin $5 \mathrm{mg}$., riboflavin $2 \mathrm{mg}$., nicotinic acid amide $20 \mathrm{mg}$., adermin $2 \mathrm{mg}$., and calcium pantothenate $3 \mathrm{mg}$. n-tetranoic acid were quantitatively determined separately. Of the unsaturated fatty acids, only the poly-unsaturated ones could be determined individually by measurement of the absorption spectrum in ultraviolet light after alkaline isomerization. It was impossible to determine the mono-unsaturated fatty acids directly, either separately or in toto. The sum of the unsaturated fatty acids was computed by subtracting the total of the saturated fatty acids from the total of all fatty acids. The iodine number also lent support to this calculation. With these restrictions the fatty acid composition of each dietary fat could be compared with that of the corresponding chyle fat. The extraction and analyses of the fat from chyle, feces and blood were carried out by the methods of van de Kamer and his colleagues (30), using the analytical method of Boldingh $(25,26)$. A mixture of the analytically pure saturated fatty acids, n-hexanoic to n-docosanoic, which contains of each fatty acid 2 to $8 \mathrm{mg}$., can be analyzed with this method so that each acid is estimated with an accuracy of about 5 per cent. The minimum amount which can be determined with this accuracy is 0.5 to $1.0 \mathrm{mg}$., depending on the molecular weight.

\section{RESULTS}

\section{The chyle fat during a low-fat diet}

The chyle fat does not give an accurate impression of the intestinal lymph fat because the chyle consists of a mixture of intestinal and non-intestinal lymph. This should be kept in mind when a comparison is made of the fatty acid composition of chyle fat with that of dietary fat. In other words, if the chyle fats are to be compared with the corresponding dietary fats, a correction must be made for the admixture with non-intestinal lymph fat. The composition of the fat in the nonintestinal lymph is unknown, but it may be assumed that chyle fat collected during a low-fat period is similar to non-intestinal lymph fat, because the fat in the chyle during such a low-fat diet can not be of intestinal origin. The correction factor was determined by analyzing the chyle fat of four low-fat periods. Both the fatty acid composition and the fat content of this chyle were practically constant in all the periods. From this it follows that the composition of the "corrected chyle fat" can be calculated by subtracting the non-intestinal fat from the chyle fat as found by analysis. Then the fatty acid pattern of the "corrected chyle fat" can be compared directly with that of the dietary fat.

The patient was on a low-fat diet for four successive periods of a week each, the amounts of 

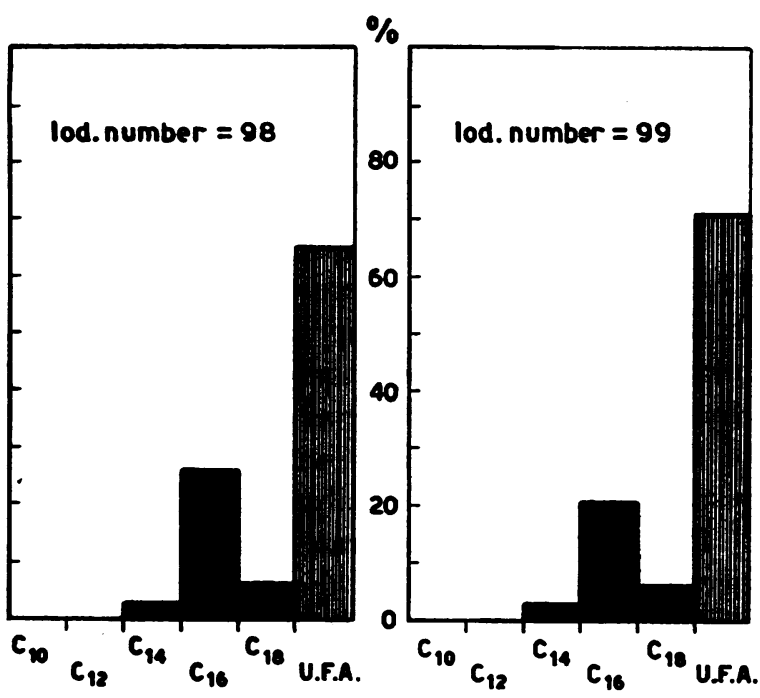

Fig. 1. Left: Composition of the Patient's Chyle Fat During a Low-Fat Diet (Less Than 1 gm. Fat DAIIY for Four WeEks). Right: Composition of the Blood fat of the Fasting Patient (During a Diet Containing Rapeseed OII)

Solid columns $=$ saturated fatty acids.

Striped columns = unsaturated fatty acids (U.F.A.)

fat given being less than $1 \mathrm{gm}$. daily. The chyle, which was of a milky white color during a regimen with normal quantities of fat ( $28 \mathrm{gm}$. daily), became transparent during the low-fat diet; in appearance it resembled blood plasma. The fat content of the chyle fell markedly, from 3.7 to about $0.6 \mathrm{gm}$. per cent.

Figure 1 shows the composition of the chyle fat during a low-fat regimen. For purposes of comparison the fatty acid pattern of the blood fat of the fasting patient during another dietary period is also given. There is a striking resemblance between the two fatty acid patterns (31). This does not imply that the forms in which these fatty acids occur (triglycerides, phospholipids, and cholesterol esters) are also similar. Table II shows that during the first period of the low-fat diet there was still an admixture with "high-fat" chyle from the preceding margarine period. In the three following periods, however, the chyle was characterized by a constant low fat content and a constant fatty acid composition. The iodine number of this chyle fat was as high as that of the fat of the blood serum of the fasting patient (see Figure 1).

Table II also shows the composition of the chyle fat of a patient with chyloascites from the Hospital for Sick Children, Great Ormond Street, London. The chyle of this nine-month-old patient was collected during a lowfat diet and was put at our disposal by Drs. W. W. Payne and A. Norman. It appears from these data that the fatty acid pattern of the chyle from their patient shows a resemblance to that of the "low-fat" chyle from ours (see Table II).

The chyle fat during a diet containing butterfat, coconut oil or margarine

The dietary fats and the chyle fats were analyzed in the usual manner, while the n-tetranoic acid content was determined separately by the method of Fairbairn and Harpur (32). The results are shown in Figure 2. The figures on the left show the percentage composition of the dietary fat in comparison with the "corrected" composition of the chyle fat. Those on the right give curves of the lymphatic absorption coefficient of each fatty acid of the dietary fat. These coefficients were cal-

TABLE I

The per cent of fatty acids in the fat from the chylothorax and chyloascites of our patient and the London patient, respectively

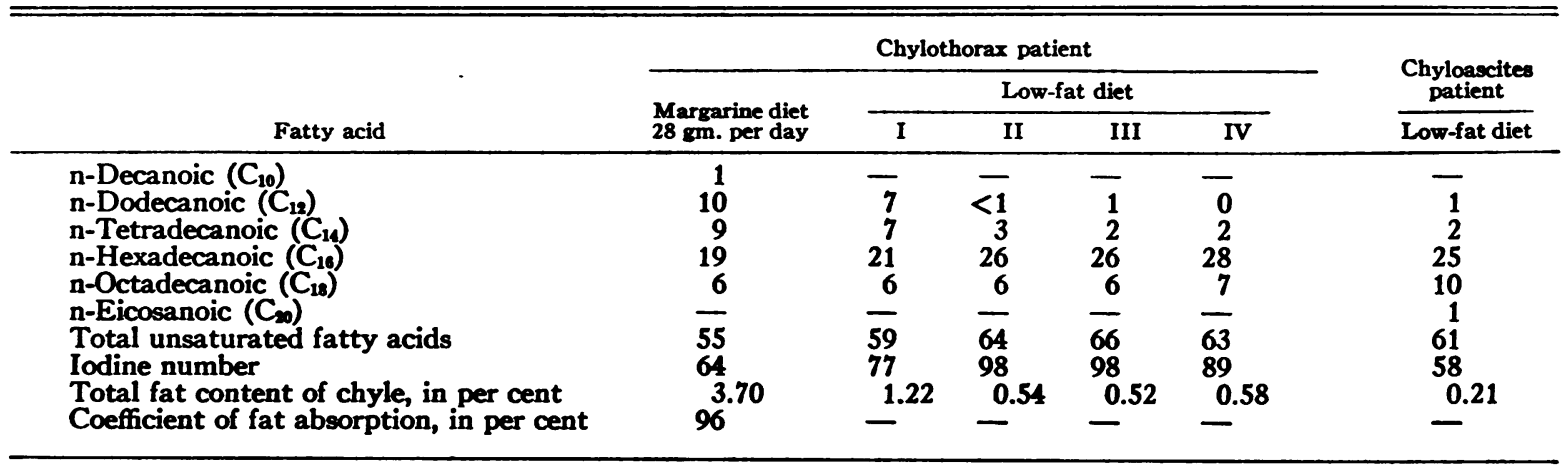



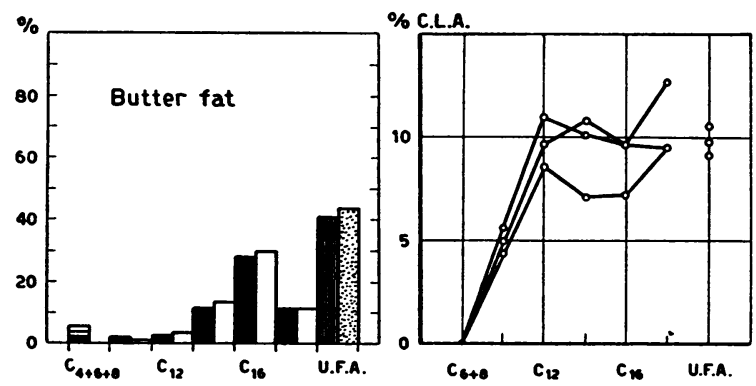

which was about $15 \mathrm{gm}$. chyle fat per diet period, is large enough for the calculation of the C.L.A. of each fatty acid as follows:

$$
\text { C.L.A. }=\frac{\text { mg. fatty acid in chyle }}{\mathrm{mg} \text {. fatty acid in food }} \times 100
$$

These figures, therefore, merely indicate how much fatty acid of the dietary fat was found in the aspirated chyle, which was only part of the total chyle. The C.L.A.'s, however, permit comparison of the various fatty acids with each other with respect to their lymphatic absorption.

The diagrams demonstrate a resemblance between the composition of the chyle fat and the dietary fat. This holds true for butterfat, coconut oil, and margarine. On closer consideration, however, certain differences become clearly manifest when the various C.L.A.'s are taken into account (see the graph on the right). n-Tetranoic, $\mathrm{n}$-hexanoic and n-octanoic acid are completely absent in the chyle; the C.L.A. of n-decanoic acid is 3 to 5 per cent; of n-dodecanoic acid 7 to 10 per cent; of n-tetradecanoic acid somewhat more. just as for $n$-hexadecanoic and n-octadecanoic acid. In this way it is demonstrated that the C.L.A. increases when the chain length of the fatty acids increases. The unsaturated fatty acids are absorbed as well as or somewhat better than the saturated n-tetradecanoic, n-hexadecanoic, and n-octadecanoic acids.

Fig. 2. Left: Composition of Dietary Fat and of Chyle Fat (Corrected) during Diets Containing Respectively Butter Fat, Coconut OIl and Margarine. Right: Coefficients of Lymphatic Absorption (C.L.A.) of The Saturated and UnSaturated Fatty Acids

Solid columns = saturated fatty acids in dietary fat. Open columns $=$ saturated fatty acids in chyle fat.

Striped columns = unsaturated fatty acids in dietary fat. Stippled columns $=$ unsaturated fatty acids in chyle fat. $\mathrm{O}-\mathrm{O}=$ "corrected values."

- $----0=$ "uncorrected values."

culated by determining the percentage of each fatty acid of the dietary fat which was recovered in the chyle. This percentage is called the "coefficient of lymphatic absorption" (C.L.A.) of the fatty acid. We are, of course, quite aware that these absorption coefficients do not indicate the total absorption of a given fatty acid via the lymph because the drainage of chyle from the patient was only partial. Only about 10 per cent of the fat from the food is recovered as chyle fat. This quantity,

\section{The chyle fat during a diet containing "capryl olive oil"'}

As it was a very striking feature that the shortchain fatty acids, $n$-tetranoic, $n$-hexanoic, and n-octanoic, were not found in the chyle when the patient was given margarine, butter, or coconut oil, it was of importance to verify this observation by administering one of these fatty acids in a greater amount in the form of triglyceride. The following data gathered from the literature are given for purposes of comparison. Kiyasu, Bloom, and Chaikoff (33) administered to rats 1-C ${ }^{14}$-labelled n-decanoic acid dissolved in maize oil. The lymphatic absorption of this free fatty acid was only 7 to 19 per cent. Frazer used tributyrine (the triglyceride of n-tetranoic acid) which was not found in the chyle after administration to rats. One should, however, be cautious in drawing con- 
clusions from these experiments because a free fatty åcid was used in the first experiment, which is an unphysiological procedure. In the second experiment a single triglyceride was employed, not to be compared with the natural fats which are composed of mixed triglycerides. Moreover, in contrast to the other long chain fatty acids, n-tetranoic acid is very readily soluble in water. Apart from these objections the experiments show at most that some short-chain fatty acids are not absorbed in the chyle or absorbed only to a very slight degree. We observed the same phenomenon in the absorption of mixed triglycerides in which the short-chain fatty acids, n-tetranoic, n-hexanoic and n-octanoic acid, from margarine, butterfat, and coconut-oil were also absent in the chyle. At the same time, however, the long-chain fatty acids were demonstrated in the chyle. This can only be explained by hydrolysis of the dietary fat.

In the experiment described below, a fat was chosen which would clearly show whether or not hydrolysis occurred. Use was made of "capryl olive oil," a fat containing 46 per cent n-octanoic acid. This was prepared by subjecting a mixture of equal parts of olive oil and tricapryline, the triglyceride of n-octanoic acid, to alkaline reesterification. In this way a mixed triglyceride was formed in which each molecule contained at least one n-octanoic acid group. ${ }^{3}$ This "capryl olive oil" was given to the patient in the usual quantities (28 gm. daily) for one week. The fat balance was normal during this period (absorption coefficient 98 per cent). The fat content of the chyle also retained a normal value (2.1 per cent). This proves that the fat absorption in general, as well as the lymphatic absorption in particular, was normal. For these reasons this experiment with a synthetic fat may be considered a physiological one.

Figure 3 shows that the chyle fat contained only 4 per cent n-octanoic acid in contrast to the dietary fat which contained 46 per cent of this acid. The C.L.A. of n-octanoic acid is only 0.70 per cent, while that of $\Delta^{9}$-octadecanoic acid is 8.6 per cent. These experiments therefore confirm the findings

\footnotetext{
3 The composition of the "capryl olive oil" was calculated as: $27.5 \mathrm{~mol}$. per cent tricapryline; $44.3 \mathrm{~mol}$. per cent "dicapryl olive oil ;" 23.9 mol. per cent "monocapryl olive oil ;" and $4.3 \mathrm{~mol}$. per cent olive oil.
}

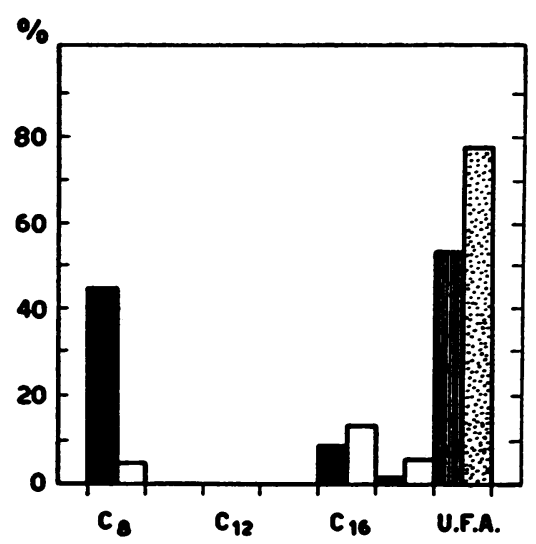

Fig. 3. Composition of Dietary fat and of Chyle Fat (Corrected) During a Diet Containing "Capryl OrIve On"

Solid columns = saturated fatty acids in dietary fat. Open columns = saturated fatty acids in chyle fat.

Striped columns $=$ unsaturated fatty acids in dietary fat. Stippled columns $=$ unsaturated fatty acids in chyle fat.

when butterfat, coconut oil, and margarine are used.

As n-octanoic acid was found in the chyle in only slight amounts, while the "capryl olive oil" was well absorbed (the fat balance was normal), it seemed acceptable that this fatty acid was absorbed via the portal vein or converted in the intestinal wall ( $<12.5 \mathrm{mg}$. per cent octanoic acid). Whether n-octanoic acid could be demonstrated in the blood was therefore investigated. Three and one-half hours after an oral dose of $28 \mathrm{gm}$. "capryl olive oil" (i.e., the whole amount for one day) venepuncture was carried out and the blood fat analyzed. n-Octanoic acid could not be demonstrated in it, and it may therefore be concluded that n-octanoic acid does not pass the liver as such but is converted in the intestine or liver.

\section{The chyle fat during a diet containing cacao-butter and hydrogenated herring oil with peanut oil}

In order to study in more detail the lymphatic absorption of the saturated fatty acids, n-hexadecanoic, n-octadecanoic, n-eicosanoic and n-docosanoic, experiments were carried out with cacaobutter, a fat containing 25 per cent $n$-hexadecanoic and 35 per cent n-octadecanoic acid, and with a hydrogenated herring oil (re-esterified with peanut oil so that the melting point was $42^{\circ} \mathrm{C}$.), a fat containing 8 per cent n-eicosanoic and 8 per cent 
n-docosanoic acid. No conclusions can be drawn regarding the absorption of $n$-hexadecanoic and n-octadecanoic acid because the cacao-butter diet was preceded by a period during which the patient suffered from enteritis. Although he seemed clinically cured, there was still present a steatorrhea (absorption coefficient $=80$ per cent), the fat of which contained much hexadecanoic and n-octadecanoic acid. The low coefficient of absorption of cacao-butter might be caused by the high percentage of stearic acid in this fat, viz. 35 per cent. This is in accordance with the results of Bloom, Chaikoff, and Reinhardt (23) who found that only 36 to 54 per cent of stearic acid, as free fatty acid dissolved in corn oil, is absorbed
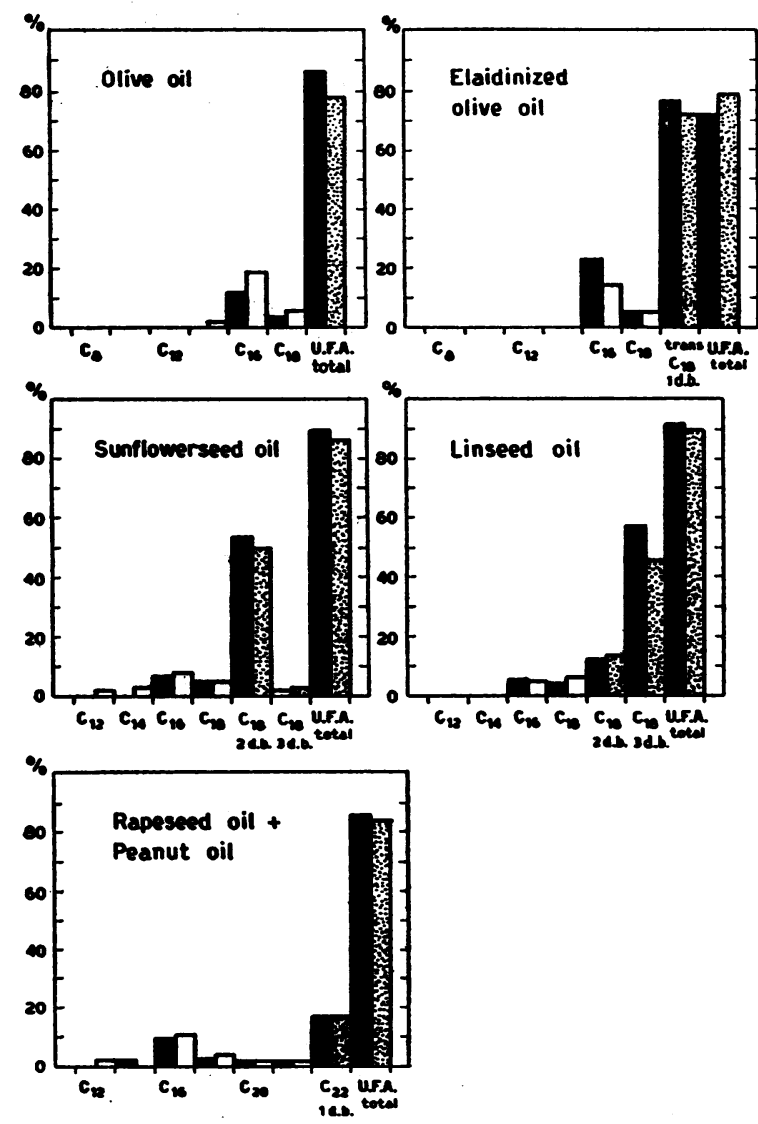

Fig. 4. Composition of Dietary Fat and of Chyle Fat (Corrected) During Diets Containing Fats with Unsaturated Fatry Acms

Solid columns $=$ saturated fatty acids in dietary fat. Open columns = saturated fatty acids in chyle fat.

Striped columns $=$ unsaturated fatty acids in dietary fat. Stippled columns $=$ unsaturated fatty acids in chyle fat. by the rat, in contrast to at least 80 per cent of shorter chain fatty acids.

It can only be deduced that n-eicosanoic $\left(\mathrm{C}_{20}\right)$ and $n$-docosanoic $\left(\mathrm{C}_{22}\right)$ acids are absorbed through the lymph. It was, however, impossible to calculate the degree of this absorption because the chyle production had fallen markedly during this period, owing to the patient's spontaneous recovery.

\section{The chyle fat during diets containing fats with un- saturated fatty acids}

In order to study more closely the absorption of various unsaturated fatty acids, $\Delta^{0}$-octadecenoic acid (cis and trans-isomers), $\Delta^{9,12}$-octadecadienoic acid, $\Delta^{9,12,15}$-octadecatrienoic acid, and $\Delta^{18}$-docosenoic acid, experiments were carried out with olive oil (containing cis- $\Delta^{9}$-octadecenoic acid), eláidinized olive oil (containing trans- $\Delta^{\circ}$-octadecenoic acid), sunflower seed oil (containing $\Delta^{9,12}$-octadecadienoic acid and $\Delta^{0,12,15}$-octadecatrienoic acid), linseed oil (idem) and rapeseed oil + peanut oil (containing $\Delta^{13}$-docosenoic acid). The results are represented in Figure 4. In all cases there was a great degree of resemblance between the composition of chyle fat and dietary fat.

\section{Summary}

The results of the entire investigation are comprised in Figure 5. The composition of the chyle fat remained practically unchanged in successive periods when the same dietary fat was given. On the other hand, when a change was made in the dietary fat a simultaneous change in the chyle fat was observed. The similarities and differences between the dietary fat and the corresponding chyle fat are also evident in the Figure.

\section{DISCUSSION}

Experiments have indicated that the fatty acid pattern of the chyle fat differs from that of the dietary fat.

Of the saturated fatty acids, n-tetranoic and $\mathrm{n}$-hexanoic are not present in the lymph, while n-octanoic is found only to a very slight degree, even if this fatty acid is present in large amounts in the dietary fat. n-Decanoic acid is found in the lymph but its absorption is less than that of n-dodecanoic, n-tetradecanoic, $\mathbf{n}$-hexadecanoic, and 


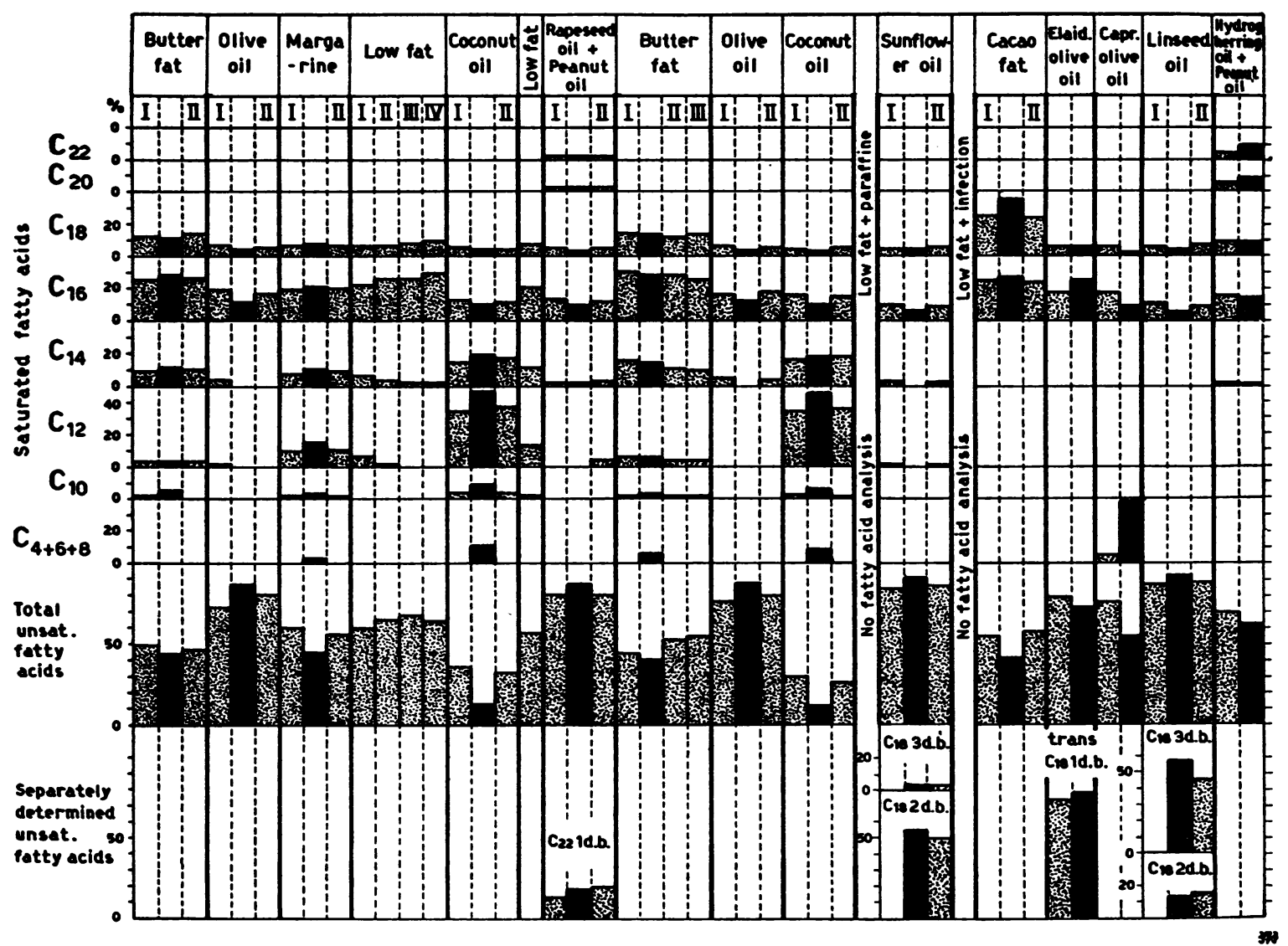

Fig. 5. Comparison of the Fatty Acids of the Dietary Fat with the Fatty Actds of the Chyle, Uncorrected Values, Represented in Chronological Order During All Diets of the Whole Period of Observation

Solid columns $=$ fatty acids of diet.

Stippled columns $=$ fatty acids of chyle.

n-octadecanoic. The four last-mentioned fatty acids are absorbed practically to the same extent. This can be deduced from Figure 6 which shows the coefficients of lymphatic absorption (C.L.A.) of the saturated fatty acids of various fats. The lines run closely parallel in the same direction which proves clearly that the C.L.A.'s of n-hexanoic, n-octanoic, n-decanoic, and n-dodecanoic acid increase as the carbon chains become longer.

In order to compare the C.L.A.'s of the fatty acids in the various periods, it is necessary to eliminate the differences in the production of chyle during these periods (see Figure 7). Although some objections may be raised to this procedure, the fatty acids found in the chyle were recalculated for a standard chyle production of $500 \mathrm{ml}$. per week. This seems to be justifiable since the fat content of the chyle was independent of the quantity of chyle produced per week and also because the amount of chyle was independent of the nature of the dietary fat. The diminution of the quantities of chyle aspirated weekly was due to the patient's spontaneous recovery.

The various unsaturated fatty acids were absorbed well. The C.L.A.'s of these fatty acids are of the same order as those of the saturated fatty acids, n-tetradecanoic, $\mathbf{n}$-hexadecanoic, and n-octadecanoic.

It follows from the difference in lymphatic absorption of the saturated fatty acids, n-octanoic, n-decanoic, and n-dodecanoic, that the dietary fat must be hydrolyzed at least partially during absorption. Otherwise, if dietary fat was absorbed without hydrolysis, there would be no difference in the absorption coefficient of the three mentioned fatty acids. 


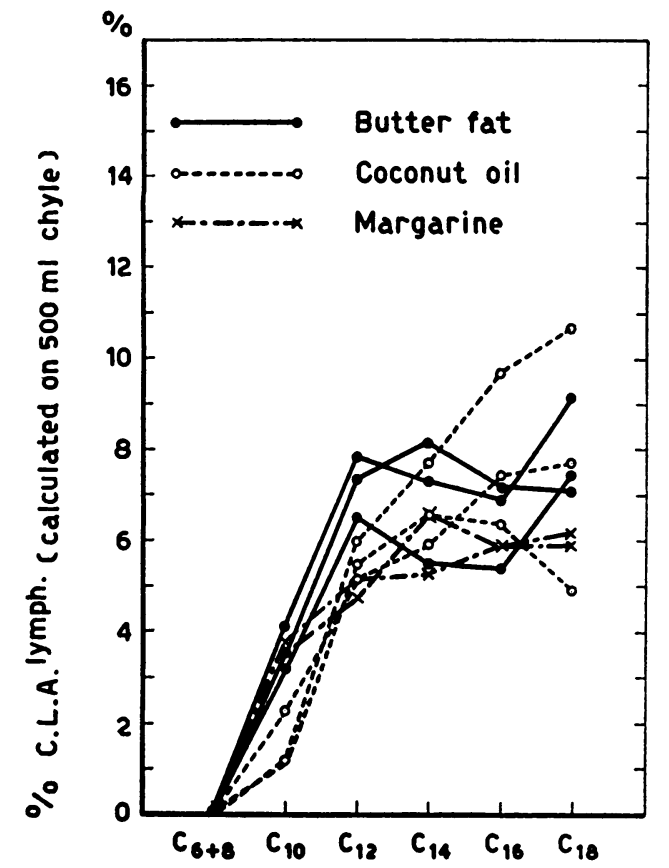

Fig. 6. Coefficients of Lymphatic Absorption (C.L.A.) of Various Dietary Fats Calculated for 500 ML. Chyle

Thus the results of the experiments with butter, margarine, and coconut oil may be explained by hydrolysis of part of the dietary fat. The other part of it might pass through the intestinal wall as triglyceride and be absorbed with the chyle. In the experiment with "capryl olive oil" almost every molecule of fat must have been hydrolyzed, as Figure 5 shows that the C.L.A. of n-octanoic acid is only 0.7 per cent, while the coefficient for the longer chain fatty acids of this fat amounts to 8.6 per cent.
The result of the very low lymphatic absorption of n-octanoic acid is also clearly manifest on comparison of the composition of dietary fat. The dietary fat contained 46 per cent n-octanoic acid while only 4 per cent of this acid was recovered in the chyle fat. The practical absence of n-octanoic acid in the chyle fat can only be explained by the assumption of a hydrolytic breakdown of almost every molecule of fat because each fat molecule contains an n-octanoic acid group. This hydrolysis, however, is not conceivable when the fat is present in the intestine in the form of tiny globules as the lipase cannot act on each fat molecule under these circumstances.

On the strength of the above considerations ("capryl olive oil"), the assumption that practically every triglyceride molecule undergoes hydrolysis does not imply that each fat molecule is hydrolyzed completely (1-2); it is quite possible that only one or two molecules of fatty acid are split off, so that mono- and diglycerides are formed.

It may be that the intestine possesses the ability of dealing with a fat, molecule by molecule. Hence the following differentiation might be possible :

1. Certain fats might be absorbed almost without hydrolysis, e.g., the greater part of the markedly unsaturated fats, olive oil, sunflower seed oil, linseed oil, and rapeseed oil.

2. Other fats must first be hydrolyzed completely or partially, viz. the fats containing shortchain fatty acids. After resynthesis, transport to the chyle follows, but the liberated short-chain

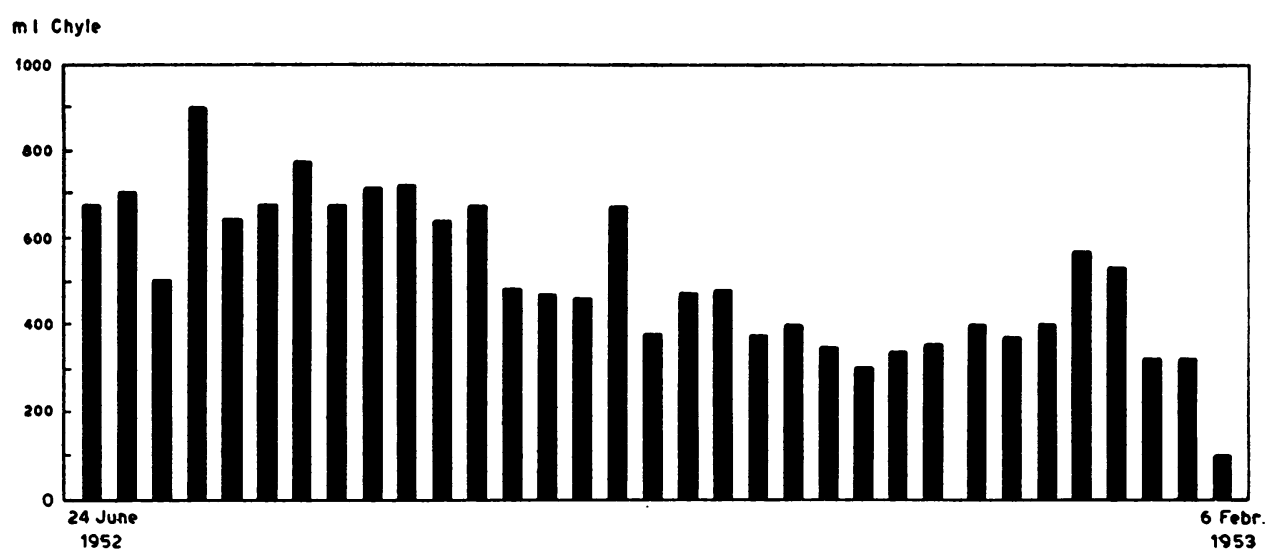

Fig. 7. The Quantity of Chyle Aspirated During the Successive Periods of the Investigation 
fatty acids are converted in the liver or in the intestinal cells. This may be the case in the absorption of "capryl olive oil," butter, margarine, and coconut oil.

This hypothesis concerning the absorption of fats implies that the droplets of the fat emulsion in the intestine (3-12) disintegrate into molecules during absorption, with, if necessary, a selection of the fatty acids of which these molecules are built up. The fat droplets in the chyle are consequently of a different composition from the fat droplets of the dietary fat in the intestinal lumen, unless we are dealing with the absorption of the unsaturated fats.

A selective splitting off of special fatty acids from the fat droplets is hardly probable, the more so because these are surrounded by a layer of mono- and diglycerides (312). Frazer's view that the fatty acids n-tetranoic to n-decanoic are removed selectively from the fat droplets after hydrolysis, owing to their solubility in water, is debatable, because only the solubility of n-tetranoic acid in water is very high, while those of $n$-hexanoic, n-octanoic and n-decanoic acid decrease successively with rapidity. The above selection may take place in the intestinal contents or in the intestinal cells.

\section{CONCLUSIONS}

It may be stated that the nature of a dietary fat decides whether or not it is hydrolyzed in the intestinal lumen and subsequently partially resynthesized to chyle fat in the intestinal wall. If there is a hydrolysis followed by resynthesis, these processes are such that the degree of lymphatic absorption is different for each fatty acid. This means that the absorption mechanism is accompanied by considerable selective capacity. Selection of triglycerides or fatty acids, however, is only possible if the fat droplets, each actually consisting of millions of molecules, disintegrate.

On the strength of this idea it is conceivable that some dietary fats (olive oil, sunflower seed oil, etc.) pass more or less unchanged into the chyle, and that in the case of other fats (butter, coconut oil, margarine, etc.) the fatty acid pattern of the chyle fat differs considerably from that of the dietary fat.

\section{SUMMARY}

The absorption of fat via the lymph was studied in an otherwise healthy child with chylothorax by administering various dietary fats during twoweek periods and comparing the fatty acid composition of dietary fat and chyle fat.

It appeared that the various fatty acids were not absorbed to the same extent. n-Hexanoic, n-octanoic and n-decanoic acid were not found, or found to only a slight degree, in the chyle. This was confirmed with an especially prepared fat, "capryl olive oil," containing 46 per cent n-octanoic acid.

The following hypothesis was evolved, based on the experiments described: Certain fats may be absorbed almost without hydrolysis, e.g., the greater part of the markedly unsaturated fatty acids (such as olive oil, sunflower seed oil, and rapeseed oil). Other fats must first be hydrolyzed completely or partially, viz., the fats containing short-chain fatty acids, such as butter, coconut oil, and "capryl olive oil." In the latter case this hypothesis cannot be reconciled with Frazer's theory of particulate absorption.

\section{REFERENCES}

1. Verzár, F., Fat absorption and transport. Influence of internal secretion on them. Arch. Sci. Physiol., 1948, 2, 43.

2. Verzár, F., and McDougall, E. J., Chapt. 10-The absorption of fats in Absorption From the Intestine. London, Longmans, Green \& Co., 1936, p. 150.

3. Frazer, A. C., Lipolysis and fat absorption. J. Physiol., 1943, 102, 329.

4. Frazer, A. C., The absorption of triglyceride fat from the intestine. Physiol. Rev., 1946, 26, 103.

5. Frazer, A. C., The digestion and absorption of fat. Arch. Sci. Physiol., 1948, 2, 15.

6. Frazer, A. C., Le système d'absorption des graisses. Bull. Soc. chim. biol., 1951, 33, 961.

7. Frazer, A. C., Fat metabolism. Ann. Rev. Biochem., 1952, 21, 245.

8. Frazer, A. C., The mechanism of fat absorption. Biochem. Soc. Symposia, 1952, 9, 5.

9. Frazer, A. C., The physiology of fat absorption in Modern Trends in Gastroenterology. F. A. Jones, ed., New York, Hoeber, 1952, p. 477.

10. Frazer, A. C., Normale und gestörte Fettresorption. Medizinische (Stuttgart), 10 Oct., 1953, p. 1317.

11. Frazer, A. C., French, J. M., Sammons, H. G., Thomas, G., and Thompson, M. D., The quantitative and qualitative investigation of fat absorption. Brit. J. Nutrition, 1949, 3, 358.

12. Frazer, A. C., and Stewart, H. C., Evidence of fat fatty acid partition in human fat absorption. Proceedings of the Physiological Society, 15 October, 1938. J. Physiol., 1938, 94, 24 P. 
13. Mattson, F. H., Benedict, J. H., Martin, J. B., and Beck, L. W., Intermediates formed during the digestion of triglycerides. J. Nutrition, 1952, 48, 335.

14. Desnuelle, P., and Constantin, M. J., Formation de glycérides partiels pendant la lipolyse de triglycerides dans l'intestin. Biochim. et. Biophys. Acta, 1952, 9, 531.

15. Kuhrt, N. H., Welch, E. A., Blum, W. P., Perry, E. S., Weber, W. H., and Nasset, E. S., Isolation and identification of monoglycerides in the intestinal contents of humans. J. Am. Oil Chem. Soc., 1952, 29, 271.

16. Borgström, B., On the mechanism of the intestinal fat absorption. II. Acta chem. Scandinav., 1951, 5, 643.

17. Reiser, R., Some recent studies on fat digestion and absorption. J. Am. Oil Chem. Soc., 1954, 31, 292.

18. Reiser, R., Bryson, M. J., Carr, M. J., and Kuiken, K. A., The intestinal absorption of triglycerides. J. Biol. Chem., 1952, 194, 131.

19. Bernhard, K., Wagner, H., and Ritzel, G., Versuche zur quantitativen Erfassung der bei der Resorption von Neutralfett eintretenden Spaltung. Helvet. chim. acta, 1952, 35, 1404.

20. Bernhard, K., Zur Beeinflussung der Fettersorption durch höhere gesättigte Fettsäuren. Helvet. physiol. pharmacol. acta, 1948, 6, 826.

21. Borgström, B., On the mechanism of the intestinal fat absorption. III. Metabolism of lipids 4. Acta physiol. Scandinav., 1952, 25, 140.

22. Borgström, B., On the mechanism of the intestinal fat absorption. IV. Metabolism of lipids 6. Acta physiol. Scandinav., 1952, 25, 291.

23. Bloom, B., Chaikoff, I. L., and Reinhardt, W. O., Intestinal lymph as pathway for transport of absorbed fatty acids of different chain lengths. Am. J. Physiol., 1951, 166, 451.
24. Favarger, $\mathbf{P}$., La résorption intestinale des acides gras chez l'animal supérieur. Exposés ann. biochim. méd., 1951, 13, 49.

25. Boldingh, J., Fatty acid analysis by partition chromatography. Rec. d. trav. chim. d. Pays-Bas, 1950, 69, 247.

26. Boldingh, J., The separation of fatty acids by chromatography. Intern. Conference Biochem. Probl. Lipids. Brussels, 1953, p. 64.

27. Fernandes, J., Kamer, J. H. van de, and Weyers, H. A., The lymphatic absorption of fat studied in a patient with a chylothorax. International Colloquim over Biochemische Problemen der Lipiden. Brussels, 1953.

28. Baldridge, R. R., and Lewis, R. V., Traumatic chylothorax. A review of the literature and report of $a$ case treated by ligation of the thoracic duct and cisterna chyli. Ann. Surg., 1948, 128, 1056.

29. Kamer, J. H. van de, Bokkel Huinink, H. ten, and Weyers, H. A., Rapid method for the determination of fat in feces. J. Biol. Chem., 1949, 177, 347.

30. Kamer, J. H. van de, Pikaar, N. A., BolssensFrankena, A., Couvée-Ploeg, C., and Ginkel, L. van, Quantitative determination of the different higher saturated fatty acids in fat from blood, chyle and feces by means of partition chromatography according to Boldingh. Biochem. J., to appear.

31. Peters, J. P., and Man, E. B., The nature and formation of thoracic duct chyle. Metabolism, 1953, 2, 30.

32. Fairbairn, D., and Harpur, R. P., The distillation, extraction and chromatographic separation of the $\mathrm{C}_{2}-\mathrm{C}_{3}$ fatty acids. Canad. J. Chem., 1951, 29, 633.

33. Kiyasu, J. Y., Bloom, B., and Chaikoff, I. L., The portal transport of absorbed fatty acids. J. Biol. Chem., 1952, 199, 415. 